\title{
Prevalence and Postpartum Screening Practice for Type 2 Diabetes following GDM in King Abdulaziz Medical City: A 3-Years Retrospective Cohort Study.
}

Abdullah Alzahrani ( $\sim$ Balhood2000@yahoo.com )

King Saud bin Abdulaziz University for Health Sciences

Daniyah Alfitni

King Abdulaziz Medical City

Maysaa Aqeel

King Abdulaziz Medical City

Ebtesam Alsulami

King Abdulaziz Medical City

Article

Keywords: Postpartum diabetes, GDM, T2DM, screening, OGTT

Posted Date: June 3rd, 2022

DOI: https://doi.org/10.21203/rs.3.rs-1233025/v2

License: (c) (i) This work is licensed under a Creative Commons Attribution 4.0 International License. Read Full License 


\section{Abstract}

\section{Aim}

GDM patients were associated to develop T2DM but mostly failed to undergo screening after delivery. This study aims to examine the practice of T2DM screening and prevalence of developing T2DM among women who had GDM in King Abdulaziz Medical City (KAMC), Saudi Arabia.

\section{Methods}

Retrospective study involving 642 pregnant women with GDM. Medical records on screenings conducted, delivery mode, GDM and diabetes family history were collected and investigated. Statistical analysis was conducted. Frequencies and percentages were used for categorical variables while means and SD for continuous. Chi-square and t-test were used to establish relationship of categorical and comparing two group means, respectively.

\section{Results}

Patients were $98.8 \%$ Saudi nationals, mean weight, height, parity and number of pregnancies were 76.96 $\mathrm{kg}, 2.74 \mathrm{~m}, 3.37$ and 1.35, respectively. Majority were obese (56.9\%), SVD (56.4\%) mode of delivery and good lifestyle (91.4\%) as management practice. OGTT was used for screening T2DM with $0 \mathrm{hr}$ fasting and 2-hrs after consuming $75 \mathrm{~g}$ of glucose, physician ordered 6 weeks after delivery. Only $20 \%$ had screening for T2DM and 3.9\% developed postpartum diabetes with high number of women not returning for ordered OGTT screening (65.6\%). Significant predictors identified were parity and mode of delivery for development of T2DM, while only mode of delivery for both screening for T2DM and management of GDM.

\section{Conclusion}

Low prevalence of developing T2DM but high number of women failed to follow the ordered OGTT screening. Effort on the implementation of OGTT screening for T2DM needs improvement.

\section{Introduction}

Type 2 diabetes (T2DM) is one of the common chronic diseases worldwide. In 2014, the World Health Organization (WHO) reported an $8.5 \%$ global prevalence of diabetes among adults above 18 years old [1]. In Saudi Arabia alone, the International Diabetes Federation (IDF) estimated a prevalence of $18.5 \%$ in 2017 [2]. T2DM is associated with various risk factors such as sedentary lifestyle, obesity, family history, ethnicity and gestational diabetes mellitus (GDM). 
Gestational diabetes mellitus (GDM) is a kind of diabetes that is diagnosed in the second or third trimester of pregnancy that was not obvious diabetes prior to pregnancy [3]. There are multiple studies showing a strong relation between GDM and developing T2DM postpartum [4-6]. In a meta-analysis which included 20 studies done between 1960 to 2009, it was found that females diagnosed with GDM had a higher tendency of developing T2DM [4]. Additionally, a 5-year prospective study done in India showed that $40 \%$ of pregnant women who had GDM developed postpartum T2DM [5]. This relationship between GDM and developing T2DM is due to various modifiable and nonmodifiable risk factors. Another meta-analysis done in 2016 on 39 cohort studies demonstrated that maternal age, BMI, ethnicity, family history of diabetes, parity, and glucose level during gestation were related to the risk of developing T2DM [6]. In 2015, a study to Saudi women by Alfadhli and colleagues estimated the prevalence of GDM at 51\% and $16.2 \%$ diagnosed by (OGTT) following both the International Association of the Diabetes and Pregnancy Study Groups (IADPSG) and the American Diabetes Association (ADA) standards, respectively [7]. Moreover, the same study also demonstrated multiple risk factors that can contribute to developing GDM such as high BMI, older maternal age, previous history and as well as family history of GDM [7].

Screening after GDM is precisely essential in order to reduce or prevent the danger of having T2DM. ADA diagnose GDM based on certain criteria through the one step or two step OGTT [3]. On the other hand, screening for T2DM after GDM is usually completed by an OGTT and is recommended 4 to 12 weeks postpartum, according to ADA guidelines of 2018 [8].

In spite of proper guidelines, some women with previous GDM are not attending their scheduled postpartum screening, and a number of studies showed that the frequency of postpartum diabetes screening is low and estimated at the range between 18.5 to $61 \%$ [9-14]. In a retrospective study done in 2018 regarding screening practices, of the 152 diagnosed with GDM, only 21 of them returned for postpartum OGTT result, and 9 of those had prediabetes [15]. The reason behind women not attending their screening appointments can be multifactorial. In Iran, Rafii and colleagues [13] conducted a study on the barriers of postpartum screening and identified that insufficient education, difficult perception regarding screening, inappropriate attitudes toward screening and delaying attitude of the patients. Additionally, in the same study patients who did not use insulin during pregnancy did not come for screening [13]. Another study showed that only higher parity and the absence of insulin during gestation were linked with noncompliance to screening [11]. Similarly, another study showed that lower parity, the use of insulin, and higher GDM glucose levels were related to higher screening rates [16].

To enhance postpartum screening, healthcare providers need to increase their patients' knowledge and understanding of the high risk of T2DM to patients with previous GDM, and also introduce factors to ease screening compliance. A study done in Saudi Arabia recommended for mothers to be screened during their children's vaccination visits for convenience [17]. The aim of this study is to examine the practice of T2DM screening after GDM and the prevalence for developing T2DM among women who have had GDM in King Abdulaziz Medical City, Ministry of National Guards Health Affairs, Jeddah, Saudi Arabia.

\section{Objectives of the study}


To examine the practice of T2DM screening after GDM and the prevalence of developing T2DM among women who have had GDM in King Abdulaziz Medical City (KAMC), Ministry of National Guards Health Affairs, Jeddah, KSA.

\section{Specific objectives :}

1. To examine the practice of T2DM screening after GDM.

2. To identify the prevalence of developing T2DM among women who have had GDM in KAMC.

\section{Patients And Methods \\ Study Area/Setting}

This study was conducted at King Abdulaziz Medical City (KAMC), Ministry of National Guards Health Affairs, Jeddah, KSA.

\section{Study Subjects}

Pregnant women who attended the Gestational diabetes mellitus (GDM) clinic from the 1st of January 2016 to 31 st of December 2018. Based on the following criteria:

\section{Inclusion criteria:}

- Pregnant woman diagnosed with GDM

\section{Exclusion criteria:}

- T2DM or pre diabetes mellitus (DM)

- Unbooked patients, no data

- Diagnosed in first trimester

- Patient Delivered outside KAMC

- Impaired oral glucose tolerance test (OGTT)

- Diagnosis not confirmed in system (outside diagnosis or no OGTT)

\section{Study Design}

This study is a 3 year retrospective cohort study.

\section{Sample Size}

All pregnant women detected with GDM from the 1st of January 2016 to 31st of December 2018, attending the GDM clinics at King Abdulaziz Medical City, Ministry of National Guards Health Affairs, Jeddah, KSA, was included in this study. 


\section{Sampling Technique}

All data of women diagnosed with GDM in the mentioned period obtained from their respective medical records and Best Care System were reviewed and included in this study.

\section{Data Collection Methods, Instruments Used, Measurements}

Data from the GDM clinic was reviewed by the investigators, and was collected from the patient's files and entered into an Excel sheet. Also, information on the development of T2DM (in these same patients) over the years period from 2016-2018 was collected and entered as well.

To identify predictors for returning for a screening test a logistic regression model was created including the following variables:

\section{Dependent variables}

- Development of type 2 diabetes.

- Returning for screening.

\section{Independent variables}

- Maternal age

BMI

- Nationality

- Parity

- Insulin during pregnancy

- Number of previous pregnancies with GDM

Please see Appendix A for Data Collection Sheet.

\section{Data Management and Analysis}

This study was analyzed using IBM SPSS version 23 (IBM Corp., Armonk, N.Y., USA) and visually presented by using GraphPad Prism version 8 (GraphPad Software., San Diego, CA, USA). A simple descriptive statistics was used to define the characteristics of the study variables through a form of counts and percentages for the categorical variables while continuous variables are presented by mean and standard deviations. To establish a relationship between categorical variables, this study used chisquare test. While for comparison of two groups' means, an independent t-test was used. These tests were done with the assumption of normal distribution. Lastly, a conventional $p$-value $<0.05$ was the criteria used to reject the null hypothesis. 
Ethical approval was obtained from the institutional review board /Ethical committee at King Abdullah International medical research center (KAIMRC) and informed written consent was taken from all participants in the study. All methods were carried out in accordance with relevant guidelines and regulations. All raw data and related materials are available, for further data information, you can contact dr.abdullah alzahrani.

\section{Results}

\section{Characteristics of the Patients}

From 1 January 2016 to 31 December 2018, a total of 642 pregnant women were identified with gestational diabetes mellitus (GDM) at King Abdulaziz Medical City and used as study samples for this particular study. More than half of the patients (65.8\%) were below 35 years old and only $34.2 \%$ were above age 35 . Almost all of these patients $(98.8 \%)$ were Saudi nationals and the remaining participants (1.2\%) were non-Saudi nationals (Table 1 ).

Out of the 642 pregnant women with GDM, only $32.9 \%$ have reported comorbidity. The most commonly observed comorbidity among the pregnant women were hypothyroidism (36), CVD (7), asthma (7), depression (5), BA (3), HTN (3), APAS (3), epilepsy (3), seizure (2), Hodgkin lymphoma (2). Aside from this, comorbidity such as PCOS, autoimmune hepatitis, dyslipidemia, hyperthyroidism, nephrectomy, post thyroidectomy, SCA, single kidney and thyrotoxicosis were observed (Table 2).

\section{Family History and Sugar Scores of Patients}

To check if the patients had inherited condition of diabetes, the family history on DM, GDM and other disease were investigated. As shown on Table 3 below, out of the 642 patients, a total of 214 had family history of DM while 211 had indicated none. However, there were 217 patients that have missing information on their family history of this disease. No history of GDM was observed to 424 patients and 218 had missing information on the records that was investigated. Other diseases/disorders such as HTN, hydrocephaly, sickle cell disease and thromboembolic disorder were also reported in the records of 96 patients that were investigated. Among the 96, majority had HTN (92), two (2) had sickle cell disease, and both hydrocephaly and thromboembolic disorder had one (1).

Sugar score of patients was also checked on the medical files retrieved. Records revealed that oral glucose tolerance test (OGTT) was done for diagnosing both GDM and Type 2 diabetes. OGTT in diagnosing GDM was done in various timing. At 0 hour, there were 546 patients that had the test with mean sugar score of 5.11 (SD $0.8 \mathrm{~min} 3.60 \mathrm{max} 12.40$ ). The highest sugar score mean was observed at 1 hour and 2 hours after consuming glucose which was 11.16 (SD $1.4 \mathrm{~min} 6.60 \mathrm{max} 18.50$ ) and 10.50 (SD 3.9 min 3.10 max 17.10), respectively. A total of 545 patients had the test 1 hour while 544 had it after 2 hours of glucose consumption. After 3 hours of glucose consumption, there were 542 patients that had the test this way and have a mean sugar score of 7.95 (SD $1.8 \mathrm{~min} 3.19 \max 17.10$ ). On the other hand OGTT as screening for and diagnosing Type 2 diabetes was done in two different timing ( 0 hour and 2 
hours) and glucose dose ( $75 \mathrm{~g}$ and $100 \mathrm{~g})$. A total of 121 patients had the test at 0 hour with mean sugar score of 5.35 (SD 0.7 min 3.4 max 9.5). After 2 hours period, the mean sugar score of the 123 patients that had this test was 6.82 (SD 2.1 min 3.0 max 16.50) (Table 4).

\section{Screening Predictors and GDM Management}

To identify predictors that would be used as basis on who among the patients should be returning for a screening test for type 2 diabetes weight, height, and parity, number of pregnancies with GDM, BMI and mode of delivery were investigated. The patients that was investigated in this study have a mean weight and height of $76.96 \mathrm{~kg}$ (SD 16.2, min $37.9 \mathrm{~kg} \max 163 \mathrm{~kg}$ ) and $2.74 \mathrm{~m}$ (SD 13.4, min $0.55 \mathrm{~m} \max 155 \mathrm{~m}$ ), respectively. Meanwhile, the mean parity observed was 3.37 (SD 2.1 min 0 max 10).

Out of the 642 patients, a total of 586 had pregnancy with GDM and having a mean of 1.35 (SD 0.7 min 1 max 5). BMl of the patients were categorized into four (4) as normal, underweight, overweight, and obese. Majority of the patients in this study were beyond on their BMI while only $10.9 \%$ fall within the normal range. There were $56.9 \%$ of the participants who were obese, $31.1 \%$ were overweight while the remaining $1.1 \%$ were underweight. The mode of delivery for 376 (59.1\%) was SVD while the 260 (40.9\%) was C/S. However, six (6) patients had no indication of neither SVD or C/S mode of delivery. In terms on the information regarding the type GDM management during pregnancy, majority of the patients $(91.4 \%)$ were following good lifestyle practices (diet and exercise) while $7.4 \%$ of them had administered insulin and only $1.3 \%$ had metformin (Table 5 ).

\section{Prevalence of Postpartum Diabetes and Screening History of Patients}

Based on the patients files investigated, out of the 642, 18 (3.9\%) patients had developed type 2 diabetes and $116(25.2 \%)$ did not have the disease during the study period covered. However, $386(70.9 \%)$ of the patients had no indication whether they had the disease or not. Also, the records reviewed did not indicate any information (missing) regarding the development of T2DM to the 182 patients.

Additionally, whether the patients had T2DM or none, the data of patients underwent a particular screening for type 2 diabetes was checked. Investigators of this study found that only 128 (20\%) was actually screened. The vast majority (511 or $80 \%$ ) was not screened and 3 had missing information. Among the 128 patients who had screening, more than half (57.6\%) reportedly screened less than 6 weeks after giving birth while $42.4 \%$ were screened more than 6 weeks after delivery. Only 3 of these patients had missing information again. Interestingly, out of the 511 patients that weren't screened, 335 $(65.6 \%)$ had the test ordered but they did not comply and in only $176(34.4 \%)$ the test was not ordered for them by the physician to do the screening (Table 6).

\section{Predictors for the Development of Type 2 Diabetes (T2DM)}

In order to identify predictors for development of T2DM, the difference between the patients that had T2DM from those doesn't have were subjected to statistical analysis against predictors like parity, number of pregnancies with GDM, age, BMI, mode of delivery and screening for T2DM of the patients. For 
this study, statistical analysis showed that predictors such as parity ( $p$-value 0.043$)$ and mode of delivery ( $p$-value 0.023 ) are significantly different at $<0.05$ level of confidence (Table 7$)$. This result reveals further that parity and mode of delivery were correlated to the development of T2DM on the patients being investigated.

\section{Predictors of Screening for Type 2 Diabetes Mellitus (T2DM)}

To determine the factors that patients would likely to get involved to screening for T2DM, information on parity, the history of having pregnancies with GDM, age, BMI and mode of delivery were investigated. As shown on Table 8, statistical analysis showed that significant difference was only observed on the mode of delivery with $p$-value of 0.014 at $<0.05$ level of confidence (Table 8). Again, this result reveals further that mode of delivery were correlated for patients to get screening for T2DM.

\section{Predictors for the Management of GDM during Pregnancy}

To identify the factors that determines the type of management mostly practiced by pregnant patients with GDM, information on the mode of delivery, whether screened for type 2 diabetes or not and if the patients developed T2DM were examined. The statistical analysis conducted showed that again, mode of delivery are significantly different having a $p$-value of 0.015 at $<0.05$ level of confidence (Table 9). This also implies that the mode of delivery determines the types of management of GDM during pregnancy.

\section{Mode of Delivery as a Predictor}

As mode of delivery was the most frequently identified predictor in this study, a closer examination of its relationship to the development of T2DM, screening for postpartum diabetes incidences and the type of management of GDM during pregnancy was done.

Figure 1 showed the differences between patients with SVD or C/S mode of delivery that had development of postpartum diabetes, patients that was screened for T2DM and the type of GDM management employed during the pregnancy period of the patients. Figure 1A showed that patients who had SVD mode of delivery were more likely to develop type 2 diabetes as compared to those that have $\mathrm{C} / \mathrm{S}$. Whereas, Figure 1B showed that patients who had C/S mode of delivery were more likely to get screened for type 2 diabetes than those patients who had SVD mode of delivery. On the other hand, Figure 1C showed that patients who had SVD mode of delivery were more likely to practice good lifestyle (diet and exercise) as a way to manage GDM during pregnancy while patients who had C/S mode of delivery were more likely to practice insulin treatment.

\section{Discussion}

Understanding the risk associated with diabetes during pregnancy and after delivery inherent to both mother and the baby has gained tremendous attention for the last few decades. However, knowing how it can be prevented and implementing meaningful efforts are equally important matter that needs to be focused on. This retrospective study was conducted to examine the current practice of Type 2 Diabetes 
Mellitus (T2DM) screening after Gestational Diabetes Mellitus (GDM). At the same time, it aims to identify the prevalence of developing T2DM among women who had GDM at King Abdulaziz Medical City in Saudi Arabia.

In this particular study, the population of pregnant women could be considered as representative of Saudi nationals (at least at Jeddah region) as reflected in their $98.8 \%$ composition. At this medical center, oral glucose tolerance test (OGTT) was the main practice of screening done both to diagnose GDM and postpartum diabetes (T2DM). To describe it further, the screening was done by either with 0 hour fasting and after 1 hour, 2 hours, or 3 hours of glucose consumption. Glucose dosages were $75 \mathrm{~g}$ and $100 \mathrm{~g}$ for screening and diagnosing, respectively. OGTT to diagnose for T2DM were usually ordered by a physician 6 weeks after delivery with 0 hour fasting and 2 hours after consuming glucose. However, many of these patients went back earlier or later than this prescribed period.

The American Diabetes Association (ADA) recommends OGTT as one of the standard test for screening postpartum diabetes and apparently KAMC is following this guideline. The practice of using OGTT in screening for GDM and T2DM among women who had GDM were reflected in the studies conducted in Saudi Arabia by Alfaldhli and colleagues (2015) and Mahzari and colleagues (2018) to name a few [7, 17].

In terms of the prevalence, this study found a $3.9 \%$ (18 out of the 460 with information) of women that have developed postpartum T2DM. This prevalence rate is much lower compared to what Mahzari and colleagues (2018) have found in Riyadh study which has $67 \%$ conversion rate to T2DM but in this study however, only 123 women were involved [17]. Another study conducted at King Khalid University Hospital (KKUH) by Wahabi and colleagues published in 2019, a 3.6\% incidence rate of postpartum diabetes was found involving 407 women with GDM [18]. Though, in this study, Wahabi and colleagues (2019) used fasting plasma glucose (FPG) and hemoglobin A1C ( $\mathrm{HbA1c}$ ) tests for screening postpartum diabetes making the result of the current study unique and incomparable at the moment [18].

Despite lower prevalence found in this study, strikingly a large portion of these population (more than $70 \%$ ) of women have no indication whether they have developed diabetes or not because there is either no records and/or missing information on it. In addition, there is high numbers (511 or $80 \%$ ) of these women did not return to undergo screening for T2DM and majority of these (335 or 65.6\%) were ordered by their attending physicians but failed to return for screening. This scenario could indicate that there is an opportunity for improvement in the existing efforts of screening T2DM of patients with GDM that involves the patient, physician and institutional levels.

A low follow-up rate of women with GDM for screening T2DM after delivery has been reported in several studies around the globe. In London, McGovern and colleagues (2014) concluded in this study that checking of females after GDM is distinctly poor regardless of the current recommendation efforts in their country.[16] In Australia, Chamberlaine and colleagues (2014) reported low screening rates of postpartum diabetes following GDM particularly in indigenous women [19]. In 2016, Eggleston and colleagues reported that in USA based on insurance claims, postpartum diabetes screening remains underutilized 
amongst commercially insured women with gestational diabetes [20]. In France, Goueslard and colleagues (2017) also reported that less than $60 \%$ of women with GDM were screened for T2DM in the first year after delivery [21]. Relative to low postpartum screening for diabetes, Rafii and colleagues identified and reported in 2017 the barriers to postpartum diabetes screening as insufficient education, difficult perception regarding screening, inappropriate attitudes toward the screening and delaying attitude [13].

This study also revealed that among several potential predictors for women returning for screening T2DM, incidence of developing T2DM and the GDM management style, mode of delivery were the most significant ones. Interestingly, statistical analysis conducted for this study presented that there are more women that had SVD mode of delivery to developed T2DM than those women who had C/S mode of delivery. But there are more women who had C/S mode of delivery to get screened for T2DM. Based on these results, it is imperative not to take less for granted the women who had GDM and had SVD mode of delivery in the screening orders because these women are more likely to developed T2DM. This particular result was not found in the studies of Saudi women by Mahzari and colleagues (2018) and Wahabi and colleagues (2018) and in contrast have age, gravidity, history of GDM, obesity and diastolic blood pressure remained the predictors of developing T2DM $[17,18]$.

It is a good thing to know that Saudi women who had GDM have low T2DM conversion. As a matter of fact, it could imply positive healthcare implementation of the country. Nonetheless, it could also mean that the onset of developing T2DM was not covered during the study period and what was actually measured where just a portion of what is supposed to. Future retrospective studies like this knowing the incidence of developing T2DM after more than 5 years after GDM was reported are also worth exploring as Kim and colleagues (2002) reported that this is the period after delivery which has high diabetes incidence [22]. An approach having short-term and long-term follow-up group of patients is also recommended to identify the proportion undergoing follow-up and measure the annual screening rates in the country and identify the trend.

The current study based on its retrospective nature has some limitations as to describe the screening practice done in this particular medical center. Records reviewed were limited that it did not indicate the reasons of not returning for OGTT to screen for T2DM. Such information is important and potentially could provide evidence-based interventions or new insights on the improvement of the current efforts on screening practice. Nevertheless, this study has unique findings that could represent the women population that had T2DM after GDM at least in Jeddah region of KSA. The authors believed that this is the first report that examines the practice of screening for diagnosing T2DM amongst women who have had GDM and also, the first to report the prevalence of developing T2DM amongst women who had GDM in this region utilizing OGTT as a screening tool.

\section{Conclusion}


Screening for T2DM of women who had GDM pregnancy in KAMC, Jeddah, Saudi Arabia was done following OGTT with 0 hour fasting and 2 hours after consuming $75 \mathrm{~g}$ of glucose 6 weeks after delivery as prescribed by a physician. Low prevalence of $3.9 \%$ was observed to women who had GDM pregnancy developed into T2DM or as postpartum diabetes. However, there is a need for an increase effort to improve the implementation of the screening practice to encourage more women and eventually to increase the number of women returning for screening T2DM.

\section{Declarations}

- Consent for publication: We confirmed that all authors have approved the manuscript for submission

- Competing interests: The author(s) declared no potential conflicts of interest with respect to the research, authorship, and/or publication of this article.

- Funding: The author(s) received no financial support for the research, authorship, and/or publication of this article.

\section{- Authors' contributions:}

Abdullah Alzahrani, ${ }^{1,2,3}$ Daniyah Alfitni, ${ }^{2}$ Maysaa Aqeel ${ }^{2}$,Ebtesam Alsulami

ES: Conceptualization, Methodology, Software

DF: Data curation, Writing- Original draft preparation.

MA: Visualization, Investigation.

AZ: Supervision

DF: Writing- Reviewing and Editing,

\section{- Availability of Data and Materials:}

All raw data and related materials are available, for further data information, you can contact dr.abdullah alzahrani.

Ethical approval from the institutional review board / Ethical committee at King Abdullah International medical research center (KAIMRC) has been obtained and informed written consent was taken from all participants in the study.

\section{References}

1. World Health Organization. World Health Day 2016: WHO calls for global action to halt rise in and improve care for people with diabetes [Accessed: 8 May 2021]. Available from: 
https://www.who.int/news/item/06-04-2016-world-health-day-2016-who-calls-for-global-action-tohalt-rise-in-and-improve-care-for-people-with-diabetes.

2. International Diabetes Federation. IDF MENA Members [Accessed: 8 May 2021]. Available from: https://idf.org/our-network/regions-members/middle-east-and-north-africa/members/46-saudiarabia.html.

3. American Diabetes Association. Classification and Diagnosis of Diabetes: \&lt;em\&gt;Standards of Medical Care in Diabetes-2018. Diabetes Care 2018;41(Supplement 1):S13. https://doi.org/10.2337/dc18-S002

4. Bellamy L, Casas JP, Hingorani AD, Williams D. Type 2 diabetes mellitus after gestational diabetes: a systematic review and meta-analysis. Lancet 2009;373(9677):1773-1779. https://doi.org/10.1016/s0140-6736(09)60731-5

5. Gupta Y, Kapoor D, Desai A, Praveen D, Joshi R, Rozati R et al. Conversion of gestational diabetes mellitus to future Type 2 diabetes mellitus and the predictive value of $\mathrm{HbA}(1 \mathrm{c})$ in an Indian cohort. Diabet Med 2017;34(1):37-43. https://doi.org/10.1111/dme.13102

6. Rayanagoudar G, Hashi AA, Zamora J, Khan KS, Hitman GA, Thangaratinam S. Quantification of the type 2 diabetes risk in women with gestational diabetes: a systematic review and meta-analysis of 95,750 women. Diabetologia 2016;59(7):1403-1411. https://doi.org/10.1007/s00125-016-3927-2

7. Alfadhli EM, Osman EN, Basri TH, Mansuri NS, Youssef MH, Assaaedi SA et al. Gestational diabetes among Saudi women: prevalence, risk factors and pregnancy outcomes. Ann Saudi Med 2015;35(3):222-230. https://doi.org/10.5144/0256-4947.2015.222

8. American Diabetes Association. Management of Diabetes in Pregnancy: \&lt;em\&gt;Standards of Medical Care in Diabetes-2018\&lt;/em\&gt. Diabetes Care 2018;41(Supplement 1):S137. https://doi.org/10.2337/dc18-S013

9. Aziz S, Munim TF, Fatima SS. Post-partum follow-up of women with gestational diabetes mellitus: effectiveness, determinants, and barriers. J Matern Fetal Neonatal Med 2018;31(12):1607-1612. https://doi.org/10.1080/14767058.2017.1321630

10. Butalia S, Donovan L, Savu A, Johnson J, Edwards A, Kaul P. Postpartum Diabetes Testing Rates after Gestational Diabetes Mellitus in Canadian Women: A Population-Based Study. Can J Diabetes 2017;41(6):613-620. https://doi.org/10.1016/j.jcjd.2016.12.013

11. Kwong S, Mitchell RS, Senior PA, Chik CL. Postpartum diabetes screening: adherence rate and the performance of fasting plasma glucose versus oral glucose tolerance test. Diabetes Care 2009;32(12):2242-2244. https://doi.org/10.2337/dc09-0900

12. Pastore I, Chiefari E, Vero R, Brunetti A. Postpartum glucose intolerance: an updated overview. Endocrine 2018;59(3):481-494. https://doi.org/10.1007/s12020-017-1388-0

13. Rafii F, Rahimparvar SFV, Mehrdad N, Keramat A. Barriers to postpartum screening for type 2 diabetes: a qualitative study of women with previous gestational diabetes. Pan Afr Med J 2017;26:54. https://doi.org/10.11604/pamj.2017.26.54.11433 
14. Tandon N, Gupta Y, Kalra S. Postpartum screening after gestational diabetes mellitus: Aiming for universal coverage. Indian J Endocrinol Metab 2015;19(1):1-4. https://doi.org/10.4103/22308210.144634

15. Cabizuca CA, Rocha PS, Marques JV, Costa T, Santos ASN, Schröder AL et al. Postpartum follow up of gestational diabetes in a Tertiary Care Center. Diabetol Metab Syndr 2018;10:2. https://doi.org/10.1186/s13098-017-0303-4

16. McGovern A, Butler L, Jones S, van Vlymen J, Sadek K, Munro $\mathrm{N}$ et al. Diabetes screening after gestational diabetes in England: a quantitative retrospective cohort study. $\mathrm{Br} \mathrm{J}$ Gen Pract 2014;64(618):e17-23. https://doi.org/10.3399/bjgp14X676410

17. Mahzari MM, Alwadi FA, Alhussain BM, Alenzi TM, Omair AA, Al Dera HS. Development of type 2 diabetes mellitus after gestational diabetes in a cohort in KSA: Prevalence and risk factors. J Taibah Univ Med Sci 2018;13(6):582-586. https://doi.org/10.1016/j.jtumed.2018.11.004

18. Wahabi H, Fayed A, Tunkar SMS, Bakhsh H, Al-Hazmi AM, Esmaeil S et al. Incidence and contributing factors of glucose intolerance in Saudi postpartum women: Sub-group analysis from RAHMA study. PLoS One 2019;14(1):e0210024. https://doi.org/10.1371/journal.pone.0210024

19. Chamberlain C, Fredericks B, McLean A, Oldenburg B, Mein J, Wolfe R. Associations with low rates of postpartum glucose screening after gestational diabetes among Indigenous and non-Indigenous Australian women. Aust N Z J Public Health 2015;39(1):69-76. https://doi.org/10.1111/17536405.12285

20. Eggleston EM, LeCates RF, Zhang F, Wharam JF, Ross-Degnan D, Oken E. Variation in Postpartum Glycemic Screening in Women With a History of Gestational Diabetes Mellitus. Obstet Gynecol 2016;128(1):159-167. https://doi.org/10.1097/aog.0000000000001467

21. Goueslard K, Cottenet J, Mariet AS, Sagot P, Petit JM, Quantin C. Early screening for type 2 diabetes following gestational diabetes mellitus in France: hardly any impact of the 2010 guidelines. Acta Diabetol 2017;54(7):645-651. https://doi.org/10.1007/s00592-017-0986-x

22. Kim C, Newton KM, Knopp RH. Gestational diabetes and the incidence of type 2 diabetes: a systematic review. Diabetes Care 2002;25(10):1862-1868.

https://doi.org/10.2337/diacare.25.10.1862

\section{Tables}


Table 1. Demographics of the patients.

\begin{tabular}{llll}
\hline Demographics & & Count & $\%$ \\
\hline Total & & 642 & 100.0 \\
\hline \multirow{2}{*}{ Age } & Below 35 & 422 & 65.8 \\
\cline { 2 - 4 } & Above 35 & 219 & 34.2 \\
\cline { 2 - 4 } & Missing & 1 & \\
\hline \multirow{2}{*}{ Nationality } & Saudi & 634 & 98.8 \\
\cline { 2 - 4 } & Non-Saudi & 8 & 1.2 \\
\end{tabular}


Table 2. Comorbidity of the patients $(\mathrm{N}=642)$.

\begin{tabular}{|c|c|c|c|}
\hline \multicolumn{2}{|l|}{ Comorbidities } & Count & $\%$ \\
\hline \multicolumn{2}{|l|}{ HTN } & 3 & 0.5 \\
\hline \multicolumn{2}{|l|}{ CVD } & 7 & 1.1 \\
\hline \multicolumn{2}{|l|}{ PCOS } & 1 & 0.2 \\
\hline \multirow{2}{*}{\multicolumn{2}{|c|}{ Others }} & 71 & 11.1 \\
\hline & & Count & $\%$ \\
\hline \multicolumn{2}{|l|}{ Total } & 71 & 100.0 \\
\hline \multirow[t]{17}{*}{ Other Specify } & APAS & 3 & 4.2 \\
\hline & Asthma & 7 & 9.9 \\
\hline & Autoimmune Heparitis & 1 & 1.4 \\
\hline & BA & 3 & 4.2 \\
\hline & Breast cancer & 2 & 2.8 \\
\hline & Depression & 5 & 7.0 \\
\hline & Dyslipidemia & 1 & 1.4 \\
\hline & Epilepsy & 3 & 4.2 \\
\hline & Hodgken lymphoma & 2 & 2.8 \\
\hline & Hyperthyroidism & 1 & 1.4 \\
\hline & Hypothyroidism & 36 & 50.7 \\
\hline & Nephrectomy & 1 & 1.4 \\
\hline & Post thyroidectomy & 1 & 1.4 \\
\hline & SCA & 1 & 1.4 \\
\hline & Seizure & 2 & 2.8 \\
\hline & Single kidney & 1 & 1.4 \\
\hline & Thyrotoxicosis & 1 & 1.4 \\
\hline
\end{tabular}


Table 3. Family history on DM, GDM and other diseases of patients.

\begin{tabular}{|c|c|c|c|}
\hline \multicolumn{2}{|l|}{ Family history } & \multirow{2}{*}{$\begin{array}{l}\text { Count } \\
642\end{array}$} & \multirow{2}{*}{$\begin{array}{l}\% \\
100.0\end{array}$} \\
\hline Total & & & \\
\hline \multirow[t]{3}{*}{ Diabetes Mellitus (DM) } & No & 211 & 49.6 \\
\hline & Yes & 214 & 50.4 \\
\hline & Missing & 217 & \\
\hline \multirow[t]{2}{*}{ Gestational Diabetes Mellitus (GDM) } & No & 424 & 100.0 \\
\hline & Missing & 218 & \\
\hline \multirow[t]{5}{*}{ Other } & No & 329 & 77.4 \\
\hline & Yes & 96 & 22.6 \\
\hline & Missing & 217 & \\
\hline & Total & Count & $\%$ \\
\hline & & 96 & 100.0 \\
\hline \multirow[t]{4}{*}{ Other Specify } & HTN & 92 & 95.8 \\
\hline & Hydrocephaly & 1 & 1.0 \\
\hline & Sickle cell disease & 2 & 2.1 \\
\hline & Thromboembolic disorder & 1 & 1.0 \\
\hline
\end{tabular}

Table 4. Oral glucose tolerance test and sugar scores of patients.

\begin{tabular}{lllllll}
\hline Test & & N & Min & Max & Mean & SD \\
\hline OGTT Dx GDM: & $0 \mathrm{Hr}$ & 546 & 3.60 & 12.40 & 5.11 & 0.8 \\
\cline { 2 - 7 } & $1 \mathrm{Hr}$ & 545 & 6.60 & 18.50 & 11.16 & 1.4 \\
\cline { 2 - 7 } & $2 \mathrm{Hr}$ & 544 & 4.70 & 94.00 & 10.50 & 3.9 \\
\cline { 2 - 7 } & $3 \mathrm{Hr}$ & 542 & 3.10 & 17.10 & 7.95 & 1.8 \\
\hline OGTT Sc Type 2: & $0 \mathrm{Hr}$ & 121 & 3.40 & 9.50 & 5.35 & 0.7 \\
\cline { 2 - 7 } & $2 \mathrm{Hr}$ & 123 & 3.00 & 16.50 & 6.82 & 2.1
\end{tabular}


Table 5. Predictors for screening type 2 diabetes and management of GDM during pregnancy.

\begin{tabular}{|c|c|c|c|c|c|}
\hline Variables & $\mathbf{N}$ & Min & Max & Mean & SD \\
\hline Weight(kg) & 637 & 37.90 & 163.00 & 76.96 & 16.2 \\
\hline Height(m) & 641 & 0.55 & 155.00 & 2.74 & 13.4 \\
\hline Parity & 642 & 0 & 10 & 3.37 & 2.1 \\
\hline Number of pregnancies with GDM & 586 & 1 & 5 & 1.35 & 0.7 \\
\hline \multirow[t]{2}{*}{ Total } & & & & Count & $\%$ \\
\hline & & & & 642 & 100.0 \\
\hline \multirow[t]{5}{*}{ BMI } & \multicolumn{3}{|c|}{ Normal } & 70 & 10.9 \\
\hline & \multicolumn{3}{|c|}{ Under weight } & 7 & 1.1 \\
\hline & \multicolumn{3}{|c|}{ Over weight } & 199 & 31.1 \\
\hline & \multicolumn{3}{|c|}{ Obese } & 364 & 56.9 \\
\hline & \multicolumn{3}{|c|}{ Missing } & 2 & \\
\hline \multirow[t]{3}{*}{ Mode of Delivery } & \multicolumn{3}{|l|}{ SVD } & 376 & 59.1 \\
\hline & \multicolumn{3}{|l|}{$\mathrm{C} / \mathrm{S}$} & 260 & 40.9 \\
\hline & \multicolumn{3}{|c|}{ Missing } & 6 & \\
\hline \multirow[t]{4}{*}{ Management of GDM during pregnancy } & \multicolumn{3}{|c|}{ Insulin } & 47 & 7.4 \\
\hline & \multicolumn{3}{|c|}{ Metformin } & 8 & 1.3 \\
\hline & \multicolumn{3}{|c|}{ Lifestyle (diet or exercise) } & 584 & 91.4 \\
\hline & \multicolumn{3}{|c|}{ Missing } & 3 & \\
\hline
\end{tabular}


Table 6. Development of type 2 diabetes and screening history of patients $(\mathrm{N}=642)$.

\begin{tabular}{llll}
\hline Postpartum Diabetes and Screening History & Count & $\%$ \\
\hline Development of Type 2 diabetes & No & 116 & 25.2 \\
\cline { 2 - 4 } & Yes & 18 & 3.9 \\
\cline { 2 - 4 } & Unknown & 326 & 70.9 \\
\cline { 2 - 4 } & Missing & 182 & \\
\hline Screened for type 2 diabetes & No & 511 & 80.0 \\
\cline { 2 - 4 } (Pregnant women who had GDM) & Yes & 128 & 20.0 \\
\cline { 2 - 4 } & Missing & 3 & \\
\hline Total & & Count & $\%$ \\
\hline If yes, specify when & & 128 & 100.0 \\
\hline Total & Less than 6 weeks & 72 & 57.6 \\
\cline { 2 - 4 } & More than 6 weeks & 53 & 42.4 \\
\cline { 2 - 4 } & Missing & 3 & \\
\hline If no, specify why & & Count & $\%$ \\
\hline & & 511 & 100.0 \\
\hline & Not ordered & 176 & 34.4 \\
\hline & Ordered but not done & 335 & 65.6 \\
\hline
\end{tabular}


Table 7. Predictors for the development of type 2 diabetes.

Variables Total $\begin{aligned} & \text { Development of Type } 2 \\ & \text { diabetes }\end{aligned}$

p-
value

\begin{tabular}{|c|c|c|c|c|c|}
\hline & & & No & Yes & \\
\hline Total & & 134 & $116(86.6 \%)$ & $18(13.4 \%)$ & - \\
\hline Parity & & 134 & $3.20 \pm 1.9$ & $4.22 \pm 2.2$ & $0.043^{a}$ \\
\hline Number of pregnanc & GDM & 128 & $1.25 \pm 0.5$ & $1.82 \pm 1.4$ & 0.120 \\
\hline Age & Below 35 & 80 & $70(87.5 \%)$ & $10(12.5 \%)$ & 0.700 \\
\hline & Above 35 & 54 & $46(85.2 \%)$ & $8(14.8 \%)$ & \\
\hline BMI & Normal & 9 & $8(88.9 \%)$ & $1(11.1 \%)$ & 0.976 \\
\hline & $\begin{array}{l}\text { Under } \\
\text { weight }\end{array}$ & 1 & $1(100.0 \%)$ & $0(0.0 \%)$ & \\
\hline & Over weight & 43 & $37(86.0 \%)$ & $6(14.0 \%)$ & \\
\hline & Obese & 81 & $70(86.4 \%)$ & $11(13.6 \%)$ & \\
\hline Mode of Delivery & SVD & 63 & $50(79.4 \%)$ & $13(20.6 \%)$ & $0.023^{b}$ \\
\hline & $\mathrm{C} / \mathrm{S}$ & 70 & $65(92.9 \%)$ & $5(7.1 \%)$ & \\
\hline $\begin{array}{l}\text { Screened for type } 2 \\
\text { diabetes }\end{array}$ & No & 7 & $6(85.7 \%)$ & $1(14.3 \%)$ & 0.952 \\
\hline & Yes & 126 & $109(86.5 \%)$ & $17(13.5 \%)$ & \\
\hline
\end{tabular}

a-significant using Independent $t$-test $@<0.05$ level.

b-significant using Chi-Square Test @ $<0.05$ level. 
Table 8. Predictors of screening for Type 2 Diabetes.

\section{Variables}

Total Screened for type 2 diabetes

value

\begin{tabular}{|c|c|c|c|c|c|c|}
\hline & & & & No & Yes & \\
\hline Total & & & 638 & $510(79.9 \%)$ & $128(20.1 \%)$ & - \\
\hline Parity & & & 639 & $3.42 \pm 2.1$ & $3.23 \pm 2.0$ & 0.348 \\
\hline Number $c$ & ancies with $\mathrm{G}$ & & 583 & $1.35 \pm 0.7$ & $1.34 \pm 0.7$ & 0.893 \\
\hline Age & Below 35 & & 420 & $340(81.0 \%)$ & $80(19.0 \%)$ & 0.374 \\
\hline & Above 35 & 218 & & $170(78.0 \%)$ & $48(22.0 \%)$ & \\
\hline BMI & Normal & & 70 & $61(87.1 \%)$ & $9(12.9 \%)$ & 0.414 \\
\hline & $\begin{array}{l}\text { Under } \\
\text { weight }\end{array}$ & 7 & & $6(85.7 \%)$ & $1(14.3 \%)$ & \\
\hline & Over weight & 197 & & $154(78.2 \%)$ & $43(21.8 \%)$ & \\
\hline & Obese & 364 & & $289(79.4 \%)$ & $75(20.6 \%)$ & \\
\hline $\begin{array}{l}\text { Mode of } \\
\text { Delivery }\end{array}$ & SVD & & 376 & $313(83.2 \%)$ & $63(16.8 \%)$ & $0.014^{\mathrm{a}}$ \\
\hline & $\mathrm{C} / \mathrm{S}$ & 259 & & $195(75.3 \%)$ & $64(24.7 \%)$ & \\
\hline
\end{tabular}

a-significant using Chi-Square Test @ $<0.05$ level. 
Table 9. Predictors for the management of GDM during pregnancy.

\begin{tabular}{|c|c|c|c|c|c|}
\hline \multirow[t]{2}{*}{ Variables } & & \multirow[t]{2}{*}{ Total } & \multicolumn{2}{|c|}{$\begin{array}{l}\text { Management of GDM during } \\
\text { pregnancy }\end{array}$} & \multirow[t]{2}{*}{$\begin{array}{l}p- \\
\text { value }\end{array}$} \\
\hline & & & Insulin & $\begin{array}{l}\text { Lifestyle (diet or } \\
\text { exercise) }\end{array}$ & \\
\hline \multirow[t]{2}{*}{ Mode of Delivery } & SVD & 372 & $19(5.1 \%)$ & $353(94.9 \%)$ & $0.015^{\mathrm{a}}$ \\
\hline & $\mathrm{C} / \mathrm{S}$ & 254 & $26(10.2 \%)$ & $228(89.8 \%)$ & \\
\hline \multirow{2}{*}{$\begin{array}{l}\text { Screened for type } 2 \\
\text { diabetes }\end{array}$} & No & 503 & $32(6.4 \%)$ & $471(93.6 \%)$ & 0.117 \\
\hline & Yes & 125 & $13(10.4 \%)$ & 112(89.6\%) & \\
\hline \multirow{3}{*}{$\begin{array}{l}\text { Development of Type } \\
2 \text { diabetes }\end{array}$} & No & 113 & $10(8.8 \%)$ & 103(91.2\%) & 0.320 \\
\hline & Yes & 18 & $3(16.7 \%)$ & $15(83.3 \%)$ & \\
\hline & Unknowr & 322 & $23(7.1 \%)$ & $299(92.9 \%)$ & \\
\hline
\end{tabular}

a-significant using Chi-Square Test @ $<0.05$ level.

\section{Supplementary}

Appendix $A$ is not available with this version

Figures 

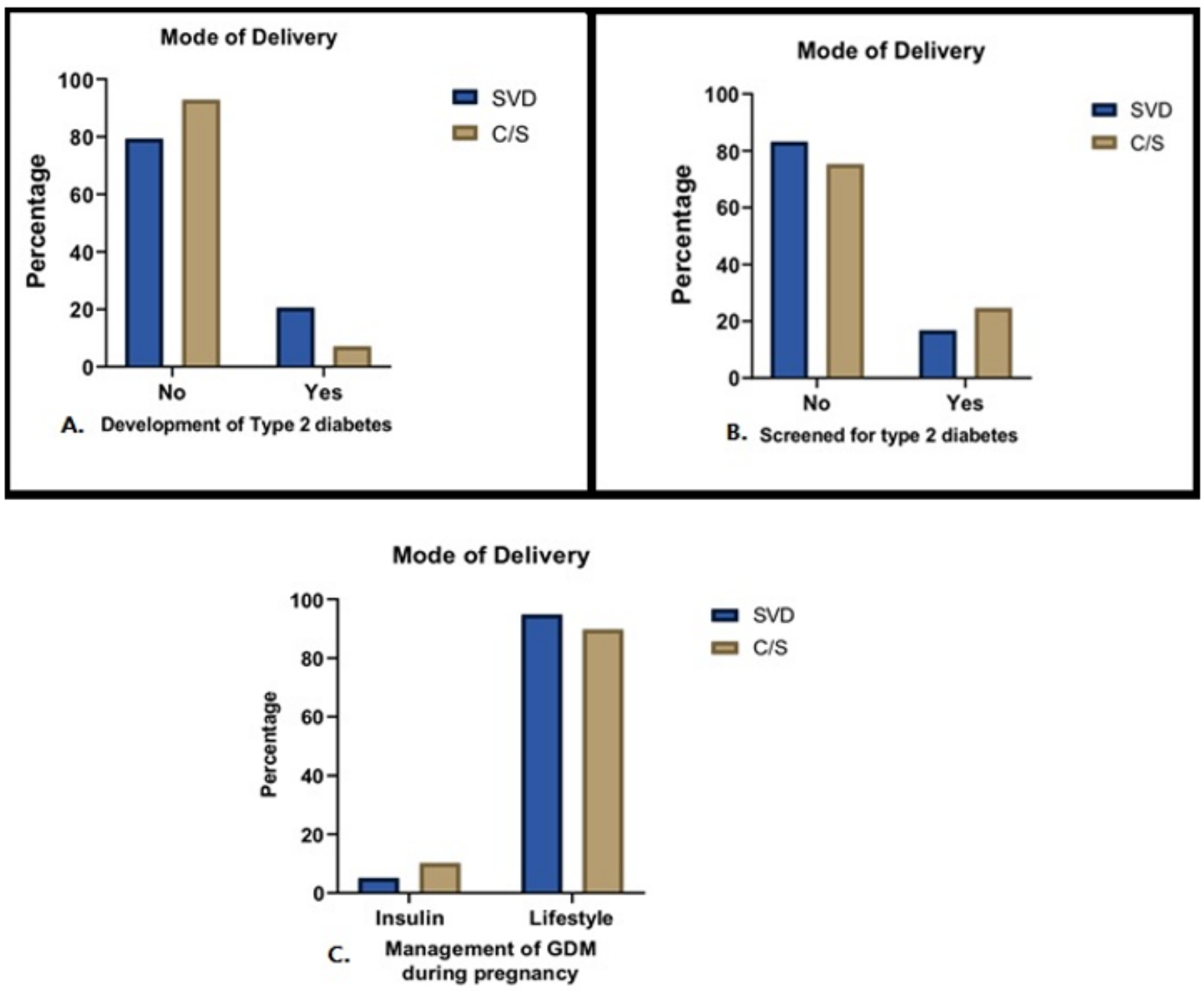

Figure 1

The difference between patients according to mode of delivery. 